\title{
Effect of thymoquinone on head and neck squamous cell carcinoma cells in vitro: Synergism with radiation
}

\author{
ULANA KOTOWSKI $^{1}$, GREGOR HEIDUSCHKA ${ }^{1}$, LORENZ KADLETZ ${ }^{1}$, TAMMER FAHIM ${ }^{1}$, RUDOLF SEEMANN $^{2}$, \\ RAINER SCHMID $^{3}$, SVEN SCHNEIDER ${ }^{1}$, ANDREAS MITTERBAUER ${ }^{4}$ and DIETMAR THURNHER ${ }^{5}$ \\ Departments of ${ }^{1}$ Otorhinolaryngology, Head and Neck Surgery, ${ }^{2}$ Cranio-Maxillofacial and Oral Surgery, \\ ${ }^{3}$ Radiotherapy and ${ }^{4}$ Thoracic Surgery, Medical University of Vienna, A-1090 Vienna; \\ ${ }^{5}$ Department of Otorhinolaryngology, Head and Neck Surgery, Medical University of Graz, A-8036 Graz, Austria
}

Received March 6, 2016; Accepted June 27, 2016

DOI: $10.3892 / \mathrm{ol} .2017 .6189$

\begin{abstract}
Thymoquinone (TQ) is the main bioactive constituent present in black seed oil (Nigella sativa); it has shown anti-inflammatory and anti-neoplastic effects in various cancer cell types. The aim of the present study was to investigate the effects of TQ on head and neck squamous cell carcinoma (HNSCC) cell lines, on its own and in combination with radiation and cisplatin, respectively. The SCC25 and CAL27 HNSCC cell lines were treated with TQ alone and in combination with cisplatin or radiation, respectively. Proliferation assays and clonogenic assays were performed. Apoptosis was detected by flow cytometry. TQ exhibited dose-dependent cytotoxicity via apoptosis in the investigated cell lines. In combination with cisplatin, TQ resulted in no significant increase in cytotoxicity. Combined with radiation, TQ significantly reduced clonogenic survival compared with each treatment method alone. TQ is a promising agent in the treatment of head and neck cancer due to its anti-proliferative and radiosensitizing properties. However, the combination of TQ with cisplatin showed no therapeutic benefit in vitro.
\end{abstract}

\section{Introduction}

Cancer, being one of the most common causes of mortality worldwide, remains as one of the great challenges of modern medicine. Head and neck squamous cell carcinoma (HNSCC) is the sixth most common cancer type in the world, with $>600,000$ mortalities every year $(1,2)$. Survival rates have not increased in the last few decades. Furthermore, significant side effects of current therapeutic strategies, including surgery and chemoradiotherapy, persist as important factors creating

Correspondence to: Professor Gregor Heiduschka, Department of Otorhinolaryngology, Head and Neck Surgery, Medical University of Vienna, Waehringer Guertel 18-20, A-1090 Vienna, Austria E-mail: gregor.heiduschka@meduniwien.ac.at

Key words: thymoquinone, radiation, cisplatin, radiosensitizer, head and neck squamous cell carcinoma dissatisfaction with the treatment (3). Rare but life-threatening complications, such as vascular erosion after radiotherapy, have been described (4). However, in cases of advanced disease, even combined treatment modalities deliver unsatisfactory results (5). Therefore, novel therapeutic substances that enhance the known effects of established therapies while reducing the undesirable side effects are required.

Thymoquinone (TQ) is a phytochemical compound derived from black cumin, Nigella sativa, a plant belonging to the Ranunculaceae family of flowering plants. Extensive research has been performed in vitro and in vivo proving it to exert anti-neoplastic, anti-inflammatory, immunomodulatory, hypoglycemic, antihypertensive, antimicrobial, anti-parasitic and antioxidant effects (6).

The antitumor effects of TQ have been investigated in tumor xenograft mice models for colon, prostate, pancreatic and lung cancer (7). Anti-tumor activity was mediated through induction of apoptosis, cell cycle arrest, generation of reactive oxygen species and anti-metastasis/anti-angiogenesis. Involved molecular targets include cellular tumor antigen p53, tumor protein $\mathrm{p} 73$, phosphatase and tensin homolog, signal transducer and activator of transcription 3, peroxisome proliferatoractivated receptor- $\gamma$ and the activation of caspases (8). Together with these promising antitumor effects, TQ has been reported to be safe in acute and chronic toxicity studies on laboratory animals, particularly when administered orally $(1,2,9)$.

In view of these findings and in the search for novel treatment methods against head and neck cancer, the present study was conducted. The aim of the study was to examine the effect of TQ in two HNSCC lines, SCC25 and CAL27, and to investigate whether TQ would exhibit a synergistic effect with cisplatin and/or radiation in vitro. Proliferation and clonogenic assays were performed, and apoptosis was measured by flow cytometry. To the best of our knowledge, this is the first study to analyze the effects of TQ in combination with cisplatin and radiation on HNSCC cell lines.

\section{Materials and methods}

Study drug. TQ was purchased from Sigma-Aldrich (Vienna, Austria), dissolved in dimethylsulfoxide (DMSO) at $80 \mathrm{mM}$ stock solution and stored at $-20^{\circ} \mathrm{C}$. Cisplatin was obtained 
from a ready-to-use infusion (Accord Healthcare Ltd., North Harrow, UK).

Cell culture. The HNSCC SCC 25 cell line was obtained from the American Type Culture Collection (Manassas, VA, USA). The HNSCC CAL27 cell line was obtained from the German Collection of Microorganisms and Cell Cultures (DSMZ, Braunschweig, Germany). Tumor cells were cultured as previously described (10). In brief, the cells were grown in RPMI medium (Cambrex, Walkersville, MD, USA) supplemented with $10 \%$ fetal bovine serum (PAA Laboratories, Linz, Austria) and $1 \%$ penicillin-streptomycin (Gibco BRL, Gaithersburg, $\mathrm{MD}, \mathrm{USA})$ at $37^{\circ} \mathrm{C}$ in a humidified atmosphere of $5 \% \mathrm{CO}_{2}$.

Cell viability assays. A Cell Counting kit-8 (CCK-8) cell viability assay (Dojindo Molecular Technologies, Gaithersburg, MD, USA) was used to determine the cytotoxic effects of TQ on the tumor cells in vitro. The cells were seeded at $3 \times 10^{3}$ cells per well into 96-well plates and incubated for $24 \mathrm{~h}$. Next, the cells were treated with increasing concentrations of TQ alone $(0-80 \mu \mathrm{M})$ and/or in combination with increasing concentrations of cisplatin $(0-32 \mu \mathrm{M})$. Aliquots of DMSO served as a control. Subsequent to $72 \mathrm{~h}$ of incubation, cell proliferation was measured by CCK-8 according to the manufacturer's protocols. Experiments were completed at least three times independently and were performed in triplicates.

Analysis of combination effects. To assess the possible synergistic effects of TQ with cisplatin, the cells were treated with increasing combinations of the two agents $(0-40 \mu \mathrm{M}$ TQ and 0-32 $\mu \mathrm{M}$ cisplatin). Dose response curves were generated and interactions were calculated with CalcuSyn ${ }^{\circledR}$ software (Version 2.0; Biosoft, Cambridge, UK) based on the Chou-Talalay equation (11).

Irradiation. The cells were irradiated using a $150-\mathrm{kV}$ X-ray machine (Gulmay D3300; Gulmay Medical Ltd., Byfleet, UK) at a dose rate of $2 \mathrm{~Gy} / \mathrm{min}$ at room temperature. The field size was $20 \times 20 \mathrm{~cm}$ and the focus-object distance was $52 \mathrm{~cm}$. For dosimetry measurements, thermoluminescence dosimeters were used.

Clonogenic assays. Clonogenic assays were performed as previously described (12). Briefly, $3-15 \times 10^{2}$ cells were seeded into 6-well plates and allowed to settle for $24 \mathrm{~h}$. Afterwards, the cells were exposed to 5-20 $\mu \mathrm{M} \mathrm{TQ}$ and/or irradiated with 2, 4,6 or 8 Gy. After 72 h, drug-containing medium was replaced by drug-free medium. After a further 10 days, the cells were washed with phosphate-buffered saline, fixed with methanol and stained with methylene blue. Colonies with $>50$ cells were regarded as survivors and counted.

Flow cytometry analysis. A total of $1 \times 10^{5}$ cells were seeded in 6-well plates. After $24 \mathrm{~h}$, the cells were treated with increased doses of TQ (SCC25 with 0, 40 and $60 \mu \mathrm{M}$; and CAL27 with $0,20$ and $40 \mu \mathrm{M})$. Cells treated with $40 \mu \mathrm{M}$ cisplatin served as a positive control. Apoptosis was measured after $48 \mathrm{~h}$ using the Annexin-V Apoptosis Detection kit (Bender MedSystems, Vienna, Austria). Apoptosis was defined as Annexin $\mathrm{V}^{+} /$propidium iodide (PI)- Annexin $\mathrm{V}^{-} / \mathrm{PI}^{+}$and Annexin $\mathrm{V}^{+} / \mathrm{PI}^{+}$results defined necrotic cells.
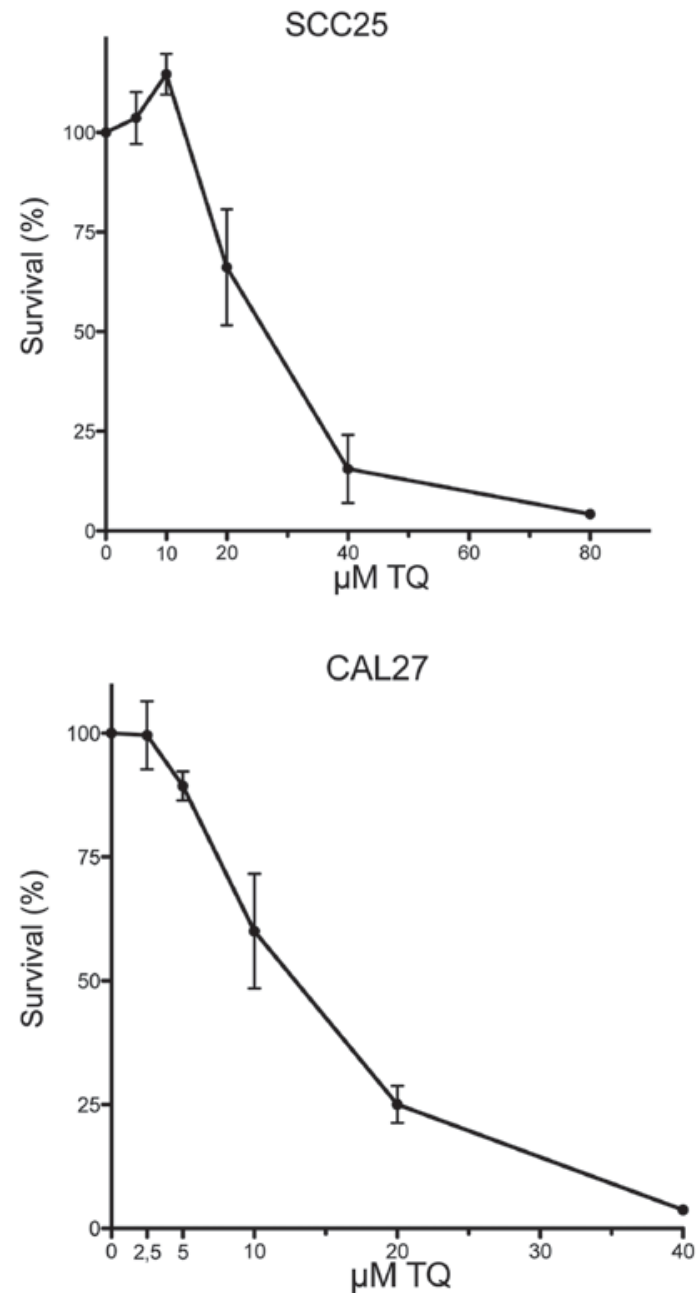

Figure 1. Dose-response curves of SCC25 and CAL27 cells following treatment with increasing doses of thymoquinone (TQ) and $72 \mathrm{~h}$ of incubation.

Statistical analysis. Statistical analysis for the cell viability assays and flow cytometry experiments was performed using SPSS $^{\circledR}$ Version 21 software (IBM ${ }^{\circledR}$ SPSS, Armonk, NY, USA) and Graph Pad 5.0 software (PRISM ${ }^{\circledR ;}$ GraphPad Software Inc., San Diego, CA, USA). For the evaluation of clonogenic survival, a linear-quadratic model was used according to the protocol by Franken et al (13). All experiments were repeated at least three times. Error bars represent the standard error of the mean (SEM) and $\mathrm{P}<0.05$ was considered to indicate a statistically significant difference.

\section{Results}

Effect of TQ on cell proliferation. The cytotoxic effect of TQ was examined in the HNSCC SCC25 and CAL27 cell lines. The cells were treated with TQ in a dose ranging from 0 to $80 \mu \mathrm{M}$. TQ displayed dose-dependent growth inhibition in the two tested cell lines. The maximal cytotoxic effect after treatment with TQ was found at 80 and $40 \mu \mathrm{M}$ in the SCC25 and CAL27 cell lines, respectively. Dose-response curves after $72 \mathrm{~h}$ of treatment are shown in Fig. 1. The half maximal inhibitory concentration $\left(\mathrm{IC}_{50}\right.$ ) values for TQ ranged from $12.12 \mu \mathrm{M}$ (CAL27) to $24.62 \mu \mathrm{M}$ (SCC25), with SEMs between $1.07 \mu \mathrm{M}$ (CAL27) and $1.10 \mu \mathrm{M}$ (SCC25). 
Table I. $\alpha$ and $\beta$ values $\pm 95 \%$ CI were estimated using curve fitting with a linear-quadratic model. ${ }^{\mathrm{a}}$

\begin{tabular}{|c|c|c|c|c|}
\hline \multirow[b]{2}{*}{ Parameter } & \multicolumn{2}{|c|}{ SCC25 } & \multicolumn{2}{|c|}{ CAL27 } \\
\hline & Value & P-value & Value & P-value \\
\hline$\alpha\left(\mathrm{Gy}^{-1}\right) \pm 95 \% \mathrm{CI}$ & $-0.01321 \pm 0.063$ & & $-0.2437 \pm 0.059$ & \\
\hline$\beta\left(\mathrm{Gy}^{-2}\right) \pm 95 \% \mathrm{CI}$ & $-0.0085 \pm 0.078$ & & $-0.0009 \pm 0.008$ & \\
\hline Dose $1 \mathrm{TQ}$ & $-1.4239 \pm 0.183$ & 0.001 & $-2.5443 \pm 0.292$ & 0.001 \\
\hline Dose 2 TQ & $-5.8584 \pm 1.296$ & 0.001 & $-6.5023 \pm 1.613$ & 0.001 \\
\hline
\end{tabular}

${ }^{a}$ To describe the enhancement of irradiation in two different doses (5 and $10 \mu \mathrm{M}$ in CAL27 cells, or 10 and $20 \mu \mathrm{M}$ TQ in SCC25 cells), a coefficient was calculated. Three independent experiments were used to calculate the $95 \%$ CIs. CI, confidence interval; TQ, thymoquinone.
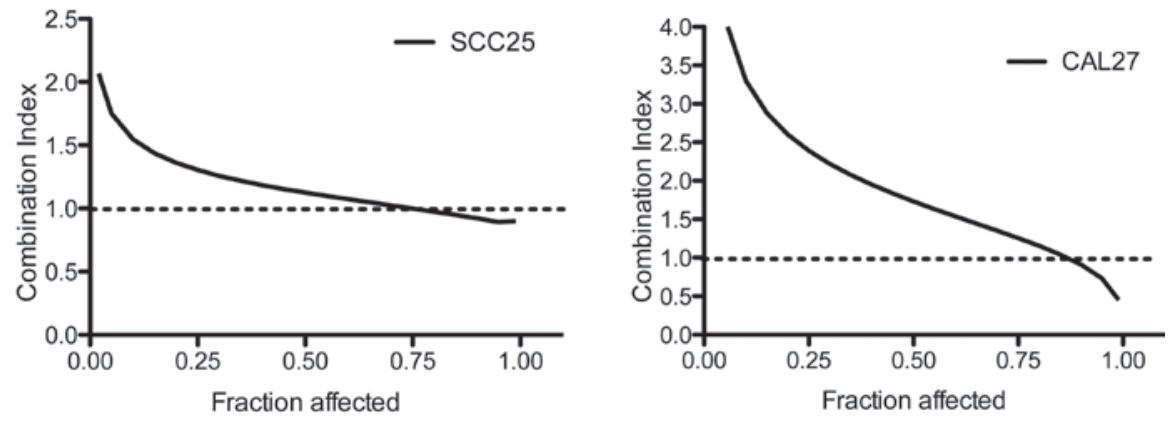

Figure 2. Combination index (CI) plot for the combination of thymoquinone and cisplatin. CI values where calculated by CalcuSyn ${ }^{\boxplus}$ software. $\mathrm{CI}=1$ indicates an additive effect, $\mathrm{CI}<1$ indicates a synergistic effect and $\mathrm{CI}>1$ indicates antagonism.
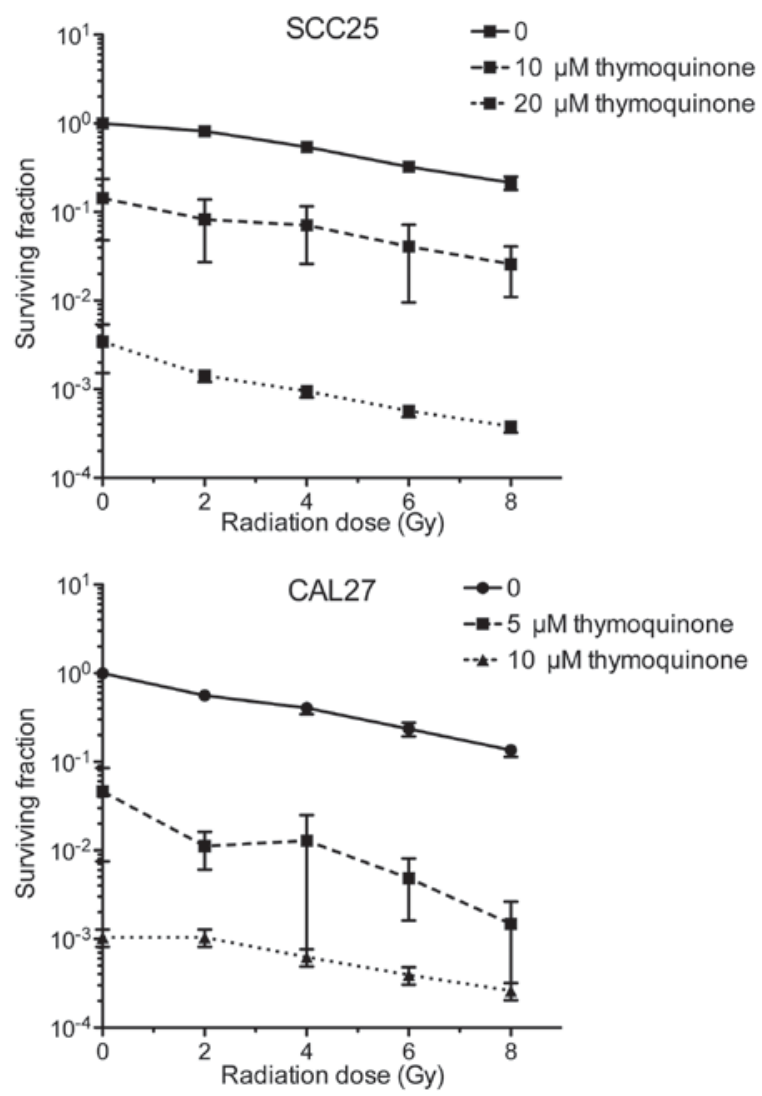

Figure 3. Clonogenic survival of cells treated with thymoquinone (TQ) alone and in combination with radiation. The cells were treated with TQ (SCC25 with 0,10 or $20 \mu \mathrm{M}$; and CAL27 with 0,5 or $10 \mu \mathrm{M}$ ) and then irradiated with $0,2,4,6$ or 8 Gy. Surviving colonies were counted after 10 days and expressed as the surviving fraction.
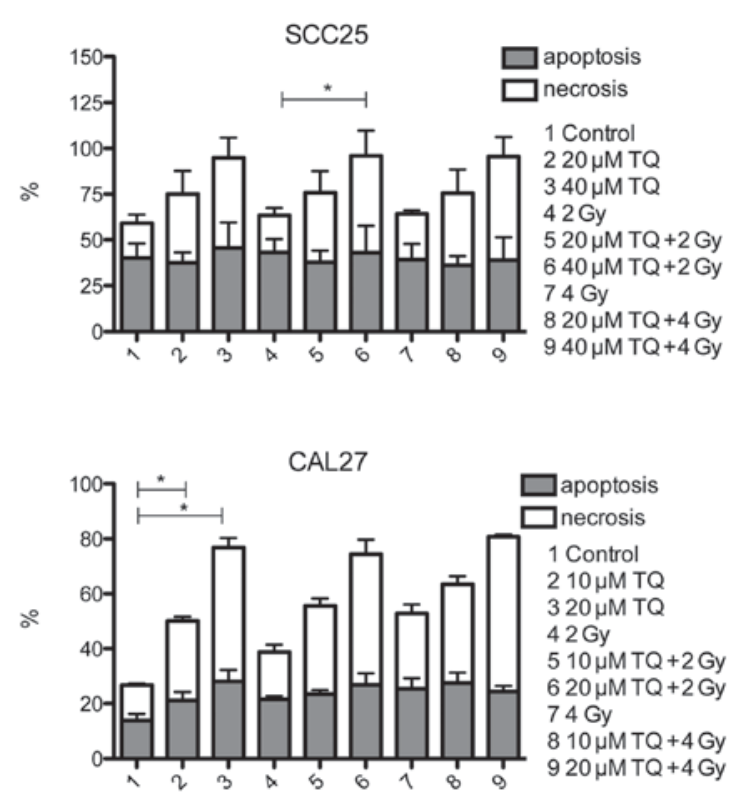

Figure 4. Evaluation of apoptosis by flow cytometry. The cells were treated with thymoquinone (TQ) (SCC25 with 0,40 and $60 \mu \mathrm{M}$; and CAL27 with 0 , 20 and $40 \mu \mathrm{M}$ ). Apoptosis was measured after $48 \mathrm{~h}$ by flow cytometry using the Annexin-V Apoptosis Detection kit. ${ }^{*} \mathrm{P}=0.0021$ for $\mathrm{SCC} 25$ cells treated with $40 \mu \mathrm{M}$ TQ +2 Gy vs. SCC 25 cells treated with 2 Gy only, $\mathrm{P}=0.0640$ for CAL27 cells treated with $10 \mu \mathrm{M}$ TQ vs. control cells and $\mathrm{P}<0.0001$ for CAL27 cells treated with $20 \mu \mathrm{M}$ TQ vs. control cells.

Combined effect of $T Q$ and cisplatin on cell proliferation. The combined effect of TQ and cisplatin was investigated. The cells were first treated with medium containing a fixed 
ratio (1:1.25) of concentrations of TQ $(0-40 \mu \mathrm{M})$ and cisplatin (0-32 $\mu \mathrm{M})$. A possible synergistic effect was calculated with CalcuSyn ${ }^{\circledR}$ software (Version 2.0, Biosoft, GB). Combination index $(\mathrm{CI})=1$ indicates an additive effect, $\mathrm{CI}<1$ indicates a synergistic effect and $\mathrm{CI}>1$ indicates antagonism. In the two cell lines, a synergistic effect could not be demonstrated (Fig. 2).

Combined effect of $T Q$ and radiation on clonogenic survival. To determine the long-term effect of treatment with radiation clonogenic assays were performed. The cells were treated with TQ (SCC25 with 0,10 , or $20 \mu \mathrm{M}$; and CAL27 with 0,5 or $10 \mu \mathrm{M})$ and then irradiated with $0,2,4,6$ or $8 \mathrm{~Gy}$. In the two tested cell lines, treatment with TQ and/or radiation led to reduced clonogenic survival. Combined treatment resulted in a synergistic inhibition of colony formation (Fig. 3; Table I).

$T Q$ induces apoptosis in HNSCC. Since treatment with TQ led to the reduced proliferation of cancer cells, flow cytometry measurements were performed to evaluate the induction of apoptosis. The cells were treated with TQ (SCC25 with 0, 40 and $60 \mu \mathrm{M}$; and CAL27 with 0,20 and $40 \mu \mathrm{M}$ ) and incubated for $48 \mathrm{~h}$. The cells treated with $40 \mu \mathrm{M}$ cisplatin served as a positive control. Treatment with TQ resulted in a distinctly increased rate of apoptosis (Fig. 4).

\section{Discussion}

The present study demonstrated for the first time a synergistic effect of TQ in HNSCC cells when combined with radiation. The experiments showed that combined treatment led to a stronger inhibition of long-term proliferation when compared with treatment with only one modality. This was demonstrated with clonogenic assays and can be interpreted as a radiosensitizing effect of TQ. This compound is known as a naturally occurring agent with an anti-proliferative effect in a variety of tumor entities (14). However, little has been published on the combined treatment with irradiation. Velho-Pereira et al examined the combined effect in human breast carcinoma cells (MCF7 and T47D) and demonstrated enhanced radiosensitivity (15). The present results support these findings.

In the present experiments, TQ combined with cisplatin exhibited no anti-proliferative synergism. This was demonstrated with proliferation assays in two HNSCC cell lines. These results differ from previous findings $(14,16)$. Jafri et al (16) combined TQ with cisplatin in lung cancer cell lines (NCI-H460 and NCI-H146) in vitro and in a mouse xenograft model using NCI-H460 in vivo. The study described a synergistic effect of the combination treatment and concluded that TQ and cisplatin appear to be an active therapeutic combination in lung cancer. However, the concentrations of TQ used in the in vitro experiments ( 80 and $100 \mu \mathrm{M})$ were considerably higher than in the present study. At these concentrations, the present cell lines showed nearly no viability even without the addition of cisplatin.

Attoub et al (14) performed in vitro experiments with TQ and/or cisplatin in cells derived from lung (LNM35), liver (HepG2), colon (HT29), melanoma (MDA-MB-435) and breast (MDA-MB-231 and MCF-7) tumors, and demonstrated that TQ synergizes with cisplatin to inhibit cellular viability. Carcinoma cells derived from head and neck tumors were not investigated.

In the present study, TQ as a single agent showed dose-dependent inhibition of cell proliferation with an $\mathrm{IC}_{50}$ ranging from 12.12 to $24.62 \mu \mathrm{M}$ after $72 \mathrm{~h}$ in the CAL27 and SCC25 cell lines, respectively. This indicated that TQ is an effective anti-proliferative substance. These values are consistent with previously reported $\mathrm{IC}_{50}$ values for $\mathrm{TQ}$ in various carcinoma cell lines $(7,17)$.

In summary, the present study showed that TQ is an effective phytochemical compound with anti-proliferative and radiosensitizing properties in head and neck cancer cells. Due to its low toxicity, TQ could possibly be used as an adjuvant to radiotherapy in the future.

\section{References}

1. Al-Ali A, Alkhawajah AA, Randhawa MA and Shaikh NA: Oral and intraperitoneal LD50 of thymoquinone, an active principle of Nigella sativa, in mice and rats. J Ayub Med Coll Abbottabad 20: 25-27, 2008.

2. Badary OA, Nagi MN, Al-Shabanah OA, Al-Sawaf HA, Al-Sohaibani MO and Al-Bekairi AM: Thymoquinone ameliorates the nephrotoxicity induced by cisplatin in rodents and potentiates its antitumor activity. Can J Physiol Pharmacol 75: 1356-1361, 1997.

3. Wiltfang J, Grabenbauer G, Bloch-Birkholz A, Leher A, Neukam FW and Kessler P: Evaluation of quality of life of patients with oral squamous cell carcinoma. Comparison of two treatment protocols in a prospective study-first results. Strahlenther Onkol 179: 682-689, 2003.

4. Greve J,Bas M, Schuler P, Turowski B, Scheckenbach K, Budach W, Bölke E, Bergmann C, Lang S, Arweiler-Harbeck D, et al: Acute arterial hemorrhage following radiotherapy of oropharyngeal squamous cell carcinoma. Strahlenther Onkol 186: 269-273, 2010.

5. Bieri S, Bentzen SM, Huguenin P, Allal AS, Cozzi L, Landmann C, Monney M and Bernier J: Early morbidity after radiotherapy with or without chemotherapy in advanced head and neck cancer. Experience from four nonrandomized studies. Strahlenther Onkol 179: 390-395, 2003.

6. Randhawa MA and Alghamdi MS: Anticancer activity of Nigella sativa (black seed)-a review. Am J Chin Med 39: 1075-1091, 2011

7. Woo CC, Kumar AP, Sethi G and Tan KHB: Thymoquinone: Potential cure for inflammatory disorders and cancer. Biochem Pharmacol 83: 443-451, 2012.

8. Gali-Muhtasib H, Diab-Assaf M, Boltze C, Al-Hmaira J, Hartig R, Roessner A and Schneider-Stock R: Thymoquinone extracted from black seed triggers apoptotic cell death in human colorectal cancer cells via a p53-dependent mechanism. Int J Oncol 25: 857-866, 2004.

9. Mansour MA, Ginawi OT, El-Hadiyah T, El-Khatib AS, Al-Shabanah OA and al-Sawaf HA: Effects of volatile oil constituents of Nigella sativa on carbon tetrachloride-induced hepatotoxicity in mice: Evidence for antioxidant effects of thymoquinone. Res Commun Mol Pathol Pharmacol 110: 239-251, 2001.

10. Kotowski U, Heiduschka G, Seemann R, Eckl-Dorna J, Schmid R, Kranebitter V, Stanisz I, Brunner M, Lill C and Thurnher D: Effect of the coffee ingredient cafestol on head and neck squamous cell carcinoma cell lines. Strahlenther Onkol 191: 511-517, 2015.

11. Chou TC and Talalay P: Quantitative analysis of dose-effect relationships: The combined effects of multiple drugs or enzyme inhibitors. Adv Enzyme Regul 22: 27-55, 1984.

12. Heiduschka G, Lill C, Schneider S, Seemann R, Kornek G, Schmid R, Kotowski U and Thurnher D: The effect of cilengitide in combination with irradiation and chemotherapy in head and neck squamous cell carcinoma cell lines. Strahlenther Onkol 190: 472-479, 2014.

13. Franken NA, Rodermond HM, Stap J, Haveman J and van Bree C: Clonogenic assay of cells in vitro. Nat Protoc 1: 2315-2319, 2006. 
14. Attoub S, Sperandio O, Raza H, Arafat K, Al-Salam S, Al Sultan MA, Al Safi M, Takahashi T and Adem A: Thymoquinone as an anticancer agent: Evidence from inhibition of cancer cells viability and invasion in vitro and tumor growth in vivo. Fundam Clin Pharmacol 27: 557-569, 2013.

15. Velho Pereira R, Kumar A, Pandey BN, Jagtap AG and Mishra KP: Radiosensitization in human breast carcinoma cells by thymoquinone: Role of cell cycle and apoptosis. Cell Biol Int 35: 1025-1029, 2011.
16. Jafri SH, Glass J,ShiR,Zhang S,Prince Mand Kleiner-HancockH: Thymoquinone and cisplatin as a therapeutic combination in lung cancer: In vitro and in vivo. J Exp Clin Cancer Res 29: 87, 2010.

17. Shoieb AM, Elgayyar M, Dudrick PS, Bell JL and Tithof PK: In vitro inhibition of growth and induction of apoptosis in cancer cell lines by thymoquinone. Int J Oncol 22: 107-113, 2003. 